Foro, Nueva época, vol. 18, núm. 2 (2015): 93-125

ISSN:1698-5583

http://dx.doi.org/10.5209/rev_FORO.2015.v18.n2.51784

\title{
CLÁUSULAS DE APERTURA AL DERECHO INTERNACIONAL DE LOS DERECHOS HUMANOS: CONSTITUCIONES IBEROAMERICANAS
}

\author{
Carolina LeÓN BASTOS \\ Coordinadora de Derechos Humanos \\ en la Facultad de Derecho \\ Universidad Anáhuac de México \\ carolina.leon@anabuac.mx \\ Víctor Alejandro Wong MERAZ \\ Profesor Investigador \\ Universidad Autónoma del Estado de México \\ awong32@yahoo.com
}

\begin{abstract}
RESUMEN
Las Constituciones iberoamericanas reflejan la preocupación de reconocer y garantizar a todos sus babitantes los derechos bumanos fundamentales del ser bumano, para lo cual integran dentro de su articulado cláusulas especiales donde reconocen la apertura a estos derechos. Para dicho reconocimiento cada Estado elige los principios y elementos que considera esenciales, y que dentro de esta reflexión se ban denominado elementos básicos de las cláusulas de apertura. El análisis comparativo parte precisamente de estos puntos que mencionan casi todos los textos constitutivos de Iberoamérica.

Palabras clave: derechos humanos, Constitución, cláusulas de apertura, tratados internacionales, dignidad humana.

\section{ABSTRACT}

Ibero-American Constitutions show their concern to recognize and guarantee basic buman rights to all their subjects, to which purpose they include in their terms and conditions special terms where they acknowledge the openness of their rights. To such extent every state chooses what it sees as main features and principles, which in this piece of work we call Basic Statements of the Opening Clauses. A compared analysis starts with such points which appear in practically every constitutional text in Latin America.
\end{abstract}

Keywords: Human Rights, Constitution, opening clauses, international treaties, human dignity. 
Carolina León y Victor A. Wong Cláusulas de apertura al Derecho internacional...

\section{ZUSAMMENFASSUNG}

Die Iberoamerikanische Verfassungen spiegeln die Absicht wider, allen Einwohnern die fundamentalen Menschenrechte zu garantieren. Daber schließen sie in ibren Gesetzeswerken besondere Klauseln ein, in welchen sie die Öffnung zu diesen Menschenrechten hin anerkennen. Um dieser Anerkennung Ausdruck zu verleihen, wäblt jeder Staat die Prinzipien und Elemente, die er als wesentlich erachtet und die in diesem Zusammenhang «Grundelemente der Öffnungsklauseln» genannt wurden. Die vorliegende vergleichende Analyse geht von diesen Grundelementen aus, die sich in fast allen Verfassungstexten Iberoamerikas befinden.

Schlüsselwörter: Menschenrechte, Verfassung, Öffnungsklauseln, Internationale Veträge, Menschenwürde.

SUMARIO: I. DERECHO INTERNACIONAL DE LOS DERECHOS HUMANOS.-II. INSERCIÓN DEL DERECHO INTERNACIONAL DE LOS DERECHOS HUMANOS EN EL ORDENAMIENTO INTERNO DE LOS ESTADOS.-III. CLÁUSULAS CONSTITUCIONALES DE APERTURA A LOS DERECHOS HUMANOS: CONSTITUCIONES HISPANOAMERICANAS.-IV. BIBLIOGRAFÍA.

\section{DERECHO INTERNACIONAL DE LOS DERECHOS HUMANOS}

La idea de difundir los derechos humanos alrededor del mundo hizo ver la necesidad de crear un Derecho especial que tuviera como uno de sus ejes la internacionalización de estos derechos. A partir de ahí entidades especialistas en la materia, principalmente la Organización de Naciones Unidas, decide, por medio de la Declaración Universal de los Derechos Humanos de 1948, que era necesario hacer respetar estos derechos a nivel mundial. La comunidad internacional asumió la tarea de crear un sistema que protegiera a los individuos del exceso en el ejercicio del poder por parte de los gobernantes: «Parecía claro que no era posible dejar entregado a la "soberanía" de cada Estado el destino de los individuos»${ }^{1}$. Con el reconocimiento internacional de estos derechos, los Estados tienen igual deber de respetarlos y de ajustar su legislación para un cumplimiento efectivo de los derechos humanos.

${ }^{1}$ C. NASH Rojas, «La protección internacional de los derechos humanos», en Seminario internacional sobre el sistema interamericano de protección de los derechos bumanos y su repercusión en los órdenes jurídicos nacionales, México DF, Suprema Corte de Justicia, 2006, p. 174. 
Otros acontecimientos importantes que ayudaron a la adopción oficial de medidas tendentes a asegurar la protección internacional de los derechos humanos fue la gran cantidad de atrocidades cometidas contra la humanidad en la Segunda Guerra Mundial, y si bien es cierto que la normativa respecto de estos derechos se empieza a observar desde finales del siglo XIX y principios del Xx, es a partir de la Segunda Guerra Mundial cuando esta necesidad se evidenció con una mayor claridad.

De esta forma nace lo que conocemos como el Derecho Internacional de los Derechos Humanos, que se define como aquel conjunto de normas y principios de Derecho internacional que reconocen e intentan proteger los derechos humanos de la persona ${ }^{2}$. Este Derecho especial se considera como un ordenamiento superior, o bien que cubre todos los ordenamientos, en cuanto otorga mayor protección respecto de los derechos humanos que los Estados; en consecuencia, ningún tratado del Derecho internacional común o costumbre internacional puede derogarlos ni restringirlos, sino sólo complementarlos y hacerlos efectivos.

Ahora bien, esta superioridad tiene su razón de ser, puesto que si las declaraciones de derechos humanos quedaran sujetas a la voluntad de los Estados, estos instrumentos y los derechos que ellos amparan perderían su razón de ser.

En este sentido, si bien es cierto que el Derecho Internacional de los Derechos Humanos (en adelante DIDH) nace del Derecho Internacional Común (en adelante DIC), también lo es que el primero posee particularidades que lo separan de éste, la principal es la posibilidad de que el ser humano reclame per se ante los órganos metanacionales —aquí el individuo es sujeto de Derecho, mientras que en el DIC sólo los Estados tienen esa posición-3.

De conformidad con el art. 41 del Pacto Internacional de Derechos Civiles y Políticos (en adelante PIDCP), la parte pasiva en la relación es el Estado. Por consiguiente, siendo precisamente cada país el principal obligado al respeto y desarrollo de los derechos humanos, sería también la única parte procesal pasiva susceptible de ser demandada o acusada por violación de los derechos humanos.

${ }^{2}$ Rodolfo Piza lo define como «el conjunto de normas y principios jurídicos internacionales relativos a los derechos humanos, y como rama especial del Derecho internacional dedicada a la promoción y protección jurídico-internacional de los derecho humanos». Véase R. Piza Rocafort y G. Trejos, Derecho Internacional de los Derechos Humanos: la Convención Americana, San José de Costa Rica, Juricentro, 1989, p. 172.

3 J. C. Hitters, Derecho Internacional de los Derechos Humanos, t. I, Buenos Aires, Ediar, 1991, p. 172. 
No obstante, no debemos olvidar que en el DIDH en los últimos años el ser humano ha pasado también a ser sujeto pasivo en cuanto a los crímenes de lesa humanidad, genocidio, crímenes de guerra y agresión. Justamente para ello se creó la Corte Penal Internacional, en la que los sujetos siempre son las personas en un sentido pasivo y activo.

La evolución de las relaciones internacionales ha dado pie para que el individuo tenga esta legitimación y ha ido superando las posturas doctrinarias nugatorias de esta posibilidad. Por ello se había advertido, desde ya hace algún tiempo, que junto a los Estados se debía reconocer la existencia de otros sujetos del DIDH.

Ahora bien, si continuamos con las particularidades del DIDH frente al DIC, encontramos que este último es un Derecho dispositivo, en cuanto está a disposición de los Estados que lo crean, modifican o amplían; en cambio, el DIDH es por su naturaleza imperativo, ya que, aunque es creado por los Estados, éstos no lo pueden eliminar después sin incurrir en responsabilidad internacional.

Si nos referimos al objeto específico de cada cual diremos que el objeto del DIC son las relaciones entre los Estados y otras personas de Derecho internacional y, de acuerdo con el desarrollo contemporáneo, también el derecho de la organización y de la actividad de los organismos internacionales. Se trata siempre de regular relaciones entre Estados o sujetos soberanos directa o indirectamente ${ }^{4}$. Por otra parte, en el DIDH lo que se regula no son relaciones entre Estados o entre organizaciones internacionales, sino derechos entre Estados y seres humanos que no aparecen como sujetos típicos de ese Derecho internacional.

En consecuencia, el DIC viene a ser «un derecho de coordinación que puede ser bilateral, plurilateral (cuando tiene por objeto el arreglo de conflicto de intereses) o multilateral (cuando tiene por objeto la coordinación de intereses hacia metas comunes), pero que siempre regula relaciones entre las partes, en el sentido de creadoras de la obligación; de manera que es no sólo un derecho de coordinación, sino también un derecho que podría llamarse autónomo» 5 .

El DIDH regula relaciones entre una parte que es el órgano de creación del Derecho, que es generalmente el Estado obligado, y los seres humanos, que son ajenos a la creación de la relación jurídica y simplemente son bene-

${ }^{4}$ E. Vargas Carreño, Introducción al Derecho Internacional, 2. ${ }^{a}$ ed., San José de Costa Rica, Juricentro, 1992, p. 278.

${ }_{5}$ Ibid., p. 280. 
ficiarios. Por tanto, podríamos decir que el DIDH es un derecho de subordinación entre partes dispares, una de ellas órgano de creación o reconocimiento y la otra beneficiario.

El DIDH está conformado por una serie de tratados, pactos, convenciones, declaraciones, etc., sobre derechos humanos de forma general y específica, por tanto, es evidente que tienen características que los hacen distintos a los comunes. En los tratados tradicionales la meta es perseguir un intercambio recíproco de beneficios y ventajas; se busca la correlación entre los derechos y los deberes entre las partes. Así, la Convención de Viena sobre Derecho de los Tratados toma en cuenta este equilibrio entre las partes de un tratado y autoriza que en caso de incumplimiento grave de sus obligaciones de una de las partes, la otra pueda dar por terminado el contrato con la suspensión parcial o total de sus efectos (art. 60) ${ }^{6}$.

Por su parte, la Corte Interamericana de Derechos Humanos en opinión consultiva declaró: «La Corte debe enfatizar, sin embargo, que los tratados modernos sobre derechos humanos en general, y en particular la Convención Americana, no son tratados multilaterales del tipo tradicional, concluidos en función de un intercambio recíproco de derechos para el beneficio mutuo de los Estados contratantes. Su objeto y fin son la protección de los derechos fundamentales de los seres humanos, independientemente de su nacionalidad, tanto frente a su propio Estado como frente a los otros Estados contratantes. $\mathrm{Al}$ aprobar estos tratados sobre derechos humanos, los Estados se someten a un orden legal dentro del cual ellos, por el bien común, asumen varias obligaciones no en relación con otros Estados, sino hacia los individuos bajo su jurisdicción» ${ }^{7}$.

Por esto el cumplimiento de las obligaciones contraídas en la Convención requiere la participación de órganos internos de los Estados, los cuales son llamados a aplicar las normas internacionales. Se dice que ésta es una de las distinciones más marcadas entre los tratados clásicos, que se limitan a reglamentar los intereses recíprocos entre las partes, y los tratados sobre derechos humanos, que están dotados de especificidad propia y, por tanto, exigen una interpretación propia guiada por los valores comunes superiores que ellos mismos abrigan.

${ }^{6}$ Con este tema, A. Dulitzki, «La aplicación de los tratados sobre derechos humanos por los tribunales locales: un estudio comparado», en M. ABREGú (comp.), La aplicación de los tratados sobre derechos humanos por los tribunales locales, Buenos Aires, Editores del Puerto, 2004, p. 35.

${ }^{7}$ Corte Interamericana de Derechos Humanos, Opinión Consultiva 2/82, del 24 de septiembre de 1982. 
En este sentido, cuando existe un incumplimiento de cláusulas en los tratados sobre derechos humanos lo que procede no es la terminación o suspensión del tratado, sino que da pie para que los Estados Parte puedan plantear denuncias en contra del infractor alegando la violación de normas.

Por otra parte, los tratados referentes a derechos humanos tienen un contenido que apunta a una garantía mínima cuyo desarrollo progresivo casi siempre se prevé; no están tampoco «restringidos por la contraposición del interés de los signatarios, ni rige el principio de reciprocidad entre los derechos y obligaciones contraídas. En tal tipo de instrumentos el destinatario es el ser humano, y los Estados no tienen un interés propio, ya que apuntan a mantener las prerrogativas del hombre. Por otra parte, la mayoría de ellos crea para los gobiernos obligaciones erga omnes» ${ }^{8}$.

El DIDH no es un derecho de excepción, es un derecho de carácter general, y más que un derecho de carácter general es un derecho extensivo. Como resultado de lo anterior, los principios interpretativos que postula el DIDH serían incompatibles con el DIC, que tiene una interpretación más restrictiva.

\section{INSERCIÓN DEL DERECHO INTERNACIONAL DE LOS DERECHOS HUMANOS EN EL ORDENAMIENTO INTERNO DE LOS ESTADOS}

El reconocimiento a nivel interno del DIDH hace necesario que los Estados se comprometan, además de a reconocerlo, a ajustar su normativa interna y a respetarlo, y, por ende, a cumplir con cualquier resolución que dicten los órganos respectivos sobre los derechos humanos. Todo lo anterior conllevaría necesariamente el cumplimiento real y efectivo de estos derechos en cada Estado.

Si seguimos las ideas de Nikken en este tema, encontramos que si bien el DIDH, en su contenido, «deriva del Derecho interno, en su ejecución deriva hacia el Derecho interno, puesto que la vocación de las obligaciones internacionales sobre derechos humanos es la de cobrar vida y ejecutarse o violarse en el ámbito doméstico» ${ }^{9}$. De ahí la importancia de la estrecha

\footnotetext{
${ }^{8}$ J. C. HitTERs, Derecho Internacional de los Derechos Humanos, t. II, Buenos Aires, Ediar, 1993, p. 185.

9 P. NikKEN, «El Derecho Internacional de los Derechos Humanos en el Derecho interno», Revista del Instituto Interamericano de Derechos Humanos, núm. 57 (2013), p. 18.
} 
interrelación entre la esfera nacional y la internacional. La interrelación ofrece una doble perspectiva.

El Estado frente al Derecho internacional está compelido a aceptar las normas a las cuales se compromete. Así igualmente, cuando se trata de derechos humanos, Nikken comenta que a partir de la aceptación de ciertos instrumentos internacionales, el Estado se ve obligado al cumplimiento de la norma de Derecho fundamental a través de lo que él llama «normas paraguas» ${ }^{10}$; así, menciona el art. 2 del Pacto Internacional de Derechos Civiles y Políticos, el cual reza: «1. Cada uno de los Estados Parte en el presente pacto se compromete a respetar y a garantizar a todos los individuos [...] 2. Cada Estado Parte se compromete a adoptar [...] las disposiciones legislativas o de otro carácter que fueren necesarias para hacer efectivos los derechos». En el mismo sentido el Pacto Internacional de Derechos Económicos, Sociales y Culturales en su art. 2, el cual menciona: «1. Cada uno de los Estados Parte [...] se compromete a adoptar medidas [...] para la plena efectividad de los derechos [...] 2. Los Estados Parte en el presente Pacto se comprometen a garantizar el ejercicio de los derechos». Con la misma idea, la Convención Americana sobre Derechos Humanos en su art. 1, titulado «Obligación de respetar los derechos», y en su art. 2, «Deber de adoptar disposiciones de Derecho interno». También en el Protocolo de San Salvador en su art. 1, «Obligación de adoptar medidas», y en su art. 2, «Obligación de adoptar disposiciones de Derecho interno».

En consecuencia, se evidencia que a partir de estas normas que imponen deberes de respetar, garantizar, satisfacer, proteger y legislar se pone de manifiesto que el Estado es jurídicamente el ente llamado a poner en ejecución el sistema de protección de los derechos humanos internacionalmente protegidos. Por su parte, la transnacionalidad es un elemento importante con respecto a la internacionalización y reconocimiento de los derechos humanos, puesto que al ser los derechos inherentes ${ }^{11}$ a la persona no dependen de la nacionalidad de ésta o del territorio donde se encuentren. Los derechos humanos están por encima del Estado y su soberanía,

${ }^{10}$ P. NikKen, «El Derecho Internacional de los Derechos Humanos en el Derecho interno», op. cit., pp. 13-14.

${ }_{11}^{11}$ Las bases de la inherencia se inspiran en diversas orientaciones filosóficas, pero lo decisivo es, más que el fundamento, el concepto resultante: se trata de derechos que se reconocen universalmente para la especie humana y cuya titularidad y ejercicio deben respetarse en cabeza de cada persona. El Estado sólo los reconoce, no los crea ni los atribuye. La protección a los derechos humanos expresa una ideología universal de la humanidad como un todo». Véase ibid., p. 51. 
y no puede considerarse que se violenta el principio de no-intervención cuando se ponen en movimiento los mecanismos organizados por la comunidad internacional para su promoción y protección. Aún más agregamos que los derechos humanos son irreversibles en el sentido de que, una vez que un determinado derecho ha sido formalmente reconocido como inherente a la persona, queda definitiva e irrevocablemente integrado a la categoría de aquellos derechos cuya inviolabilidad debe ser respetada y garantizada. Por consiguiente, el respeto a los derechos humanos implica que la actuación de los órganos del Estado no puede traspasar los límites que le señalan los derechos humanos como atributos inherentes a la dignidad de la persona y superiores al poder del Estado.

La aplicación del DIDH en el Derecho interno de los Estados se ha visto envuelta en problemas continuos por el hecho, principalmente, de que la naturaleza de ambos es muy distinta, como lo comentamos con anterioridad; mientras que el segundo «es un derecho de integración y subordinación, debido a que origina un solo orden jurídico cuyos sujetos, activos y pasivos, quedan subordinados al poder estatal», el primero «es un derecho de coordinación, que tiende a ser derecho de cooperación entre los Estados, en especial en el seno de las organizaciones internacionales, universales o regionales» ${ }^{12}$.

El principal conflicto que se presenta al enfrentar estos dos sistemas es el de la independencia que tiene cada uno de ellos y también la prioridad o prelación que les corresponde. Lo que se debe tener claro es que las normas transnacionales no pretenden reemplazar a las domésticas, que siguen siendo la plataforma principal de protección y de promoción de las prerrogativas de la persona; por ello, el Derecho internacional tiene por meta complementar al doméstico, es decir, cubrir sus vacíos. «El sistema internacional no crea derechos, se apoya en el interno, de ahí lo que se ha dado en llamar la mediatización del primero. Su función prístina en tales casos es presionar a los Estados para que lo acaten a través de los distintos modelos de control que posee» ${ }^{13}$.

A pesar de su importancia, no son iguales todas las rutas de inserción de los derechos humanos de fuente internacional en el Derecho nacional, ni en todas partes aquellos derechos cuentan con la misma prelación frente al resto de las normas internas. Finalmente, el funcionamiento concreto de uno de aquellos derechos no goza siempre de la misma ejecutividad.

12 R. Valverde, Los Derechos Humanos, San José de Costa Rica, EUNED, 1992, p. 136.

13 J. C. Hitters, Derecho Internacional de los Derechos Humanos, op. cit., t. I, p. 208. 
No obstante, debemos acotar en este punto que la aceptación local de los derechos humanos internacionales conlleva implícitamente la obligación de asegurar la efectividad de los mismos, garantizar «la reparación de los daños causados, así como para investigar seriamente los hechos cuando ello sea preciso para establecer la verdad, identificar a los culpables y aplicarles las sanciones pertinentes» ${ }^{14}$.

En este orden de ideas, un punto medular del tema es que en la incorporación de los derechos internacionales de derechos humanos al ámbito nacional se deben distinguir tres temas: el primero se refiere a los medios de incorporación del tratado internacional al Derecho interno, esto es, al «cómo» y al «cuándo» el derecho humano supranacional rige en la esfera local nacional; el segundo alude a la valoración jurídica del tratado, y, por ende, de los derechos en él enunciados, en relación con el resto de las normas nacionales; el tercero se conecta con la operatividad —inmediata o retardada - del derecho humano de fuente internacional una vez incorporado al Derecho local. De cualquier forma, la incorporación al ámbito nacional de derechos humanos enunciados en una convención o tratado internacional da a dichos derechos un fundamento «reforzado» de aplicación de tipo normativo, axiológico y hasta fáctico ${ }^{15}$.

Ahora bien, aunque de manera particular cada Estado otorgue distinta jerarquía a los instrumentos internacionales, es importante delimitar que la norma clave para un adecuado funcionamiento de este tema es la utilización del principio pro homine, es decir, siempre debe prevalecer la norma que otorgue mayores beneficios a la persona, por lo cual no se trata de importancia jerárquica de instrumentos, sino de la prevalencia de los derechos de las personas. No obstante nuestra posición anotada en el párrafo que antecede, cuando se habla de este tipo de tratados la principal discusión es, precisamente, el conflicto jerárquico entre una norma constitucional y una disposición de un tratado sobre derechos humanos.

Algunos autores hablan sobre el carácter de derecho mínimo que revisten este tipo de documentos. Esto quiere decir que estos instrumentos tienen dos sentidos: primero, que en ellos sólo se incluyen los derechos fundamentales, y segundo, que las «fórmulas normativas tienen el

${ }^{14}$ Así también, P. NikKen, «El Derecho Internacional de los Derechos Humanos en el Derecho interno», op. cit., p. 43.

${ }_{15}$ N. Pedro SagüES, «Mecanismos de incorporación de los tratados internacionales sobre derechos humanos al Derecho interno», en L. GonzÁlez Volio (coord.), Presente y futuro de los derechos humanos. Ensayos en honor a Fernando Volio Jiménez, San José de Costa Rica, Instituto Interamericano de Derechos Humanos, 1998, p. 300. 
detalle mínimo descriptivo de esos derechos y de su contenido, con elasticidad y generalidad lexicales para facilitar la ratificación y adhesión de los Estados, de modo que el Derecho interno de éstos no tropiece con barreras demasiado rígidas y disponga de suficiente margen reglamentario interno, compatible con la aludida apertura de las disposiciones normativas internacionales» ${ }^{16}$.

Antonio Cançado explica que la columna vertebral del sistema universal de los derechos humanos ha sido, precisamente, los tratados sobre este tema. Coincidimos con el autor cuando comenta que estos instrumentos deben ser examinados en sus efectos en el Derecho interno, puesto que no es posible concebir la ratificación de un tratado de derechos humanos y privarlo al mismo tiempo de efectos directos en su Derecho interno. Por otra parte, encontramos el principio que estipula que ningún Estado puede alegar Derecho interno para dejar de cumplir con una obligación internacional.

En consecuencia, cuando un tratado sobre derechos humanos ha sido incorporado al Derecho interno obliga a todos los poderes que integran esa Nación en todos los ámbitos, de dirección, de legislación, de ejecutividad y de seguridad, en cuanto a reparación del daño.

\section{CLÁUSULAS CONSTITUCIONALES DE APERTURA AL DERECHO INTERNACIONAL DE LOS DERECHOS HUMANOS: CONSTITUCIONES IBEROAMERICANAS}

El DIDH se introduce en los ordenamientos estatales a través de los tratados internacionales que éstos ratifican. No obstante, dentro de la normativa propia de cada Nación se establecen las reglas de tratamiento para estos instrumentos en términos generales. En los últimos tiempos se han incorporado además, a las Constituciones estatales, normas de apertura a los derechos humanos consagrados en los tratados internacionales, con la finalidad de ampliar el espectro de protección de estos derechos. Así, al convertirse en cierta forma en derechos constitucionales serán directamente aplicables y gozarán de la protección que la propia Constitución ofrece a los derechos contenidos en ella, independientemente de su regulación o desarrollo legislativo ${ }^{17}$.

16 A. CAnÇAdo Trindade, «Desafíos de la protección internacional de los derechos humanos al final del siglo XX», en Seminario sobre Derechos Humanos, La Habana-San José de Costa Rica, Instituto Interamericano de Derechos Humanos, 1997. p. 112.

17 A. BREWER CARÍAs, «La aplicación de los tratados internacionales sobre derechos 
La inclusión dentro del texto constitucional de prescripciones como las cláusulas de apertura se convierte en una dinámica a la que se están uniendo prácticamente todos los países iberoamericanos, puesto que, además de la protección intrínseca que se le otorga a los derechos humanos, la idea obedece a una razón práctica como lo es evitar dislocaciones entre los sistemas internos y externos de protección de los derechos humanos, con lo que a la vez se otorga seguridad jurídica a los aplicadores de estas normas ${ }^{18}$.

En este sentido se habla, por una parte, de una inserción explícita cuando los ordenamientos constitucionales contemplan expresamente los derechos humanos y les dan una supremacía constitucional, los constitucionalizan, les dan superioridad sobre las leyes o bien los asimilan con las leyes ${ }^{19}$. Por otra parte, se explica que existe la inserción implícita, y aquí es donde se alude a las cláusulas abiertas o numerus apertus ${ }^{20}$.

Por nuestra parte, la finalidad de este apartado es analizar estas normas abiertas constitucionales para entender cómo cada Estado avanza en su protección sin tocar de manera profunda los bloques de constitucionalidad que cada uno tiene establecidos. Es evidente que en la recepción nacional de un Tratado Internacional sobre Derechos Humanos se otorgan diversos rangos de jerarquización; las cuatro principales categorías son: a) supraconstitucionalización, b) constitucionalización, c) subconstitucionalización de primer grado y d) equiparación legislativa ${ }^{21}$.

humanos en el ordenamiento interno. Estudio de Derecho constitucional comparado latinoamericano», en El sistema interamericano de protección de los derechos bumanos y su repercusión en los órdenes jurídicos internos, México DF, Poder Judicial de la Federación de la Suprema Corte de Justicia de la Nación, 2008, p. 523.

${ }_{18}$ Así, C. F. Ponce Martínez, Tribunal constitucional y tratados de derechos bumanos, Zaragoza, Egido, 2002, p. 46.

19 P. Nikken, «El Derecho Internacional de los Derechos Humanos en el Derecho interno», op. cit., pp. 43 y ss.

${ }^{20}$ Ibid., p. 50.

21 «a) La doctrina de la "supraconstitucionalización" afirma la supremacía de los tratados sobre la Constitución local y determina que la validez del tratado y su vigencia en un Estado depende de los que diga el Derecho internacional. b) El método de la "constitucionalización" opta por declarar con rango constitucional a ciertos documentos internacionales por voluntad del constituyente, quien así los reconoce también como Derecho local supremo. En este caso tales derechos prevalecen sobre el resto del ordenamiento jurídico nacional subconstitucional. c) El procedimiento de la "subconstitucionalización de primer grado" indica que los tratados deben subordinarse, tanto en su contenido como en la forma de incorporación al Derecho local, a las reglas de la constitucional nacional (por ende, pueden pecar de inconstitucionalidad), pero que, satisfechos a esos recaudos, son "supralegales", esto es, que se encuentran en un escalón superior sobre las leyes internas y no pueden ser alterados por ellas. d) El mecanismo de la "equiparación legislativa" nivela los tratados internacionales y los derechos de esa fuente con una ley común. Deben, pues, conformarse 
En cuanto a la primera de estas jerarquías, el instrumento internacional posee un estatus jurídico privilegiado, está por encima de cualquier regla del Derecho interno, incluso por encima de la propia Constitución. Esto quiere decir que el tratado rige a pesar de que se oponga a algún precepto de la Constitución política. Indirectamente significa que el tratado puede reformar la Constitución ${ }^{22}$. Por otra parte, la interpretación de las normas constitucionales siempre debe, en estos casos, realizarse conforme a las normas de los tratados internacionales sobre derechos humanos. En referencia a la segunda de las jerarquías, al darles la misma categoría que los derechos incluidos en la Constitución, los derechos humanos se ven revestidos de la misma protección y efectividad que los incorporados en el texto. La siguiente denominación se refiere a que los derechos provenientes de los tratados internacionales están por debajo de la Constitución, pero por encima de las leyes generales, y, por último, la equiparación legislativa hace alusión a la igualdad de la que gozan los derechos humanos y los derechos incorporados en las leyes generales del país.

Ahora bien, la redacción de las cláusulas abiertas en las Constituciones iberoamericanas es prácticamente la misma en la mayoría de ellas; no obstante, en algunos de los textos constitucionales encontramos redacciones no homogéneas y con particularidades especiales.

En este sentido, para realizar una comparación de cláusulas abiertas en cuanto a elementos a considerar es necesario detallar todos los puntos que se toman en cuenta en la redacción de estas cláusulas de apertura a los derechos humanos y a los que nos tomaremos la libertad de acotar con la sigla EBCA (Elementos Básicos de las Cláusulas de Apertura). En consecuencia, extraemos que estos puntos claves son los que a continuación se enuncian: 1) inherencia a la persona humana; 2) forma de gobierno;3) dignidad; 4) principio de soberanía del pueblo; 5) los derechos fundamentales (o derechos pertenecientes al pueblo); 6) Derecho internacional y tratados internacionales; 7) la legalidad, y 8) principio cristiano de justicia social.

Es necesario empezar con la Constitución chilena, puesto que resulta particularmente interesante. El texto no cuenta con una cláusula de apertu-

a la Constitución en forma y contenido. Se incorporan al Derecho local como una ley más y pueden ser modificados por una ley posterior». Véase N. PEDRo SAGUÉs, «Mecanismos de incorporación de los tratados internacionales sobre derechos humanos al Derecho interno», op. cit. pp. 313-314.

22 En este sentido también C. Ayala Corao, «La jerarquía constitucional de los tratados relativos a derechos humanos y sus consecuencias», en R. Méndez SiLva (coord.), Derecho Internacional de los Derechos Humanos. Memoria del VII Congreso Iberoamericano de Derecho Constitucional, México DF, UNAM, 2002, pp. 41-49. 
ra con una redacción similar a la mayoría de las Constituciones que analizaremos a continuación, empero es la más clara de todas las cláusulas de apertura de las Constituciones iberoamericanas, puesto que es completamente notoria su posición de recibo de derechos humanos, en el sentido de que en el párrafo segundo del art. 5 menciona claramente en su redacción que el catálogo de derechos constitucionales se encuentra abierto a cualquier otro derecho esencial que no se encuentre enumerado dentro de su articulado.

«Art. 5. ${ }^{\circ}$ [...] El ejercicio de la soberanía reconoce como limitación el respeto a los derechos esenciales que emanan de la naturaleza humana. Es deber de los órganos del Estado respetar y promover tales derechos, garantizados por esta Constitución, así como por los tratados internacionales ratificados por Chile y que se encuentren vigentes.

La Constitución explicita un aseguramiento genérico a la existencia de derechos esenciales, lo que da lugar a un catálogo de derechos abierto, ya que el constituyente reconoce sus eventuales limitaciones y está consciente del desarrollo progresivo de los derechos y garantías acorde a la naturaleza y necesidades esenciales del ser humano».

Si seguimos con el esquema propuesto, después de analizar el artículo podemos decir que el texto considera el punto primero de los EBCA en relación a la inherencia de los derechos fundamentales a la persona humana, e incluso agregaríamos que el punto 6 también se toma en cuenta, por cuanto refiere a la protección de los derechos provenientes de los tratados internacionales ratificados por Chile.

Ahora bien, la redacción de la cláusula abierta, generalmente aceptada, es la que encontramos en la Carta Magna de Bolivia, la cual localizamos en el art. 13, inciso $\mathrm{II}^{23}$. Este documento constitucional nos presenta la fórmula más sencilla de todas las Constituciones iberoamericanas, puesto que no menciona ningún elemento específico como requisito para que un derecho entre a formar parte de la protección constitucional. Su redacción es la siguiente:

«II. Los derechos que proclama esta Constitución no serán entendidos como negación de otros derechos no enunciados».

No hay especificación de qué tipo de derechos pueden incluirse en el documento constitucional; no obstante, entendemos, desde nuestra óptica

${ }^{23}$ Constitución Política del Estado Plurinacional de Bolivia, 2009. 
de protección de los derechos fundamentales, que se refiere directamente a éstos. Por su parte, el inciso III alude a la jerarquía, y, en consecuencia, deducimos que los instrumentos sobre derechos humanos ratificados por Bolivia prevalecen en el orden interno; igualmente la interpretación debe hacerse con base en los tratados internacionales sobre este tema.

Es importante acotar que el texto constitucional boliviano explica que no existe jerarquía entre derechos, y eso, a nuestro criterio, es lo correcto, puesto que aunque se le otorguen distintas jerarquías a los instrumentos que contienen derechos humanos, el posicionamiento de los mismos a nivel interno no se relaciona con la protección que los derechos deben recibir $^{24}$.

Después del texto constitucional boliviano, que no contiene elementos básicos para la consideración de las cláusulas abiertas, iniciamos el comparativo con Constituciones que únicamente especifican la inherencia a la dignidad de la persona humana como punto básico. Encontramos así la Constitución de Guatemala, la cual coincide con el anterior texto constitucional, puesto que en art. 44 manifiesta expresamente que los derechos contenidos dentro del documento constitucional no excluyen otros inherentes a la persona; en este caso recurre al punto primero de los EBCA:

«Art. 44. Derechos inherentes a la persona humana. Los derechos y garantías que otorga la Constitución no excluyen otros que, aunque no figuren expresamente en ella, son inherentes a la persona humana».

Por su parte, en el art. 46 ahonda más en este sentido cuando anuncia la preeminencia sobre el Derecho interno del Derecho internacional en materia de derechos humanos ${ }^{25}$. En este caso se coloca a la Constitución por debajo de los derechos humanos emanados de instrumentos internacionales; se infiere que es cuando otorguen mayores beneficios y cuando se utilice el principio por homine para su interpretación. En consecuencia, la

${ }^{24}$ Art. 13, inciso III: «La clasificación de los derechos establecida en esta Constitución no determina jerarquía alguna ni superioridad de unos derechos sobre otros. Los tratados y convenios internacionales ratificados por la Asamblea Legislativa Plurinacional que reconocen los derechos humanos y que prohíben su limitación en los Estados de excepción prevalecen en el orden interno. Los derechos y deberes consagrados en esta Constitución se interpretarán de conformidad con los tratados internacionales de derechos humanos ratificados por Bolivia» (Constitución Política del Estado Plurinacional de Bolivia, 2009).

${ }_{25}$ «Art. 46. Preeminencia del Derecho internacional. Se establece el principio general de que en materia de derechos humanos, los tratados y convenciones aceptados y ratificados por Guatemala tienen preeminencia sobre el Derecho interno» (Constitución Política de la República de Guatemala, 1985). 
determinación expresa de Guatemala es de la máxima protección posible para los derechos fundamentales.

En Paraguay es muy claro el art. $45^{26}$ al especificar los derechos y garantías no enunciados dentro del documento constitucional. Allí estipula que no existe negación por parte de los expresados hacia otros derechos fundamentales inherentes a la personalidad humana, que constituye el punto 1 de los EBCA, al igual que la Constitución guatemalteca citada. La redacción del texto, sin embargo, utiliza la expresión «personalidad humana» en lugar de «persona humana»:

«Art. 45. De los derechos y garantías no enunciados. La enunciación de los derechos y garantías contenidos en esta Constitución no debe entenderse como negación de otros que, siendo inherentes a la personalidad humana, no figuren expresamente en ella. La falta de ley reglamentaria no podrá ser invocada para negar ni para menoscabar algún derecho o garantía».

El mismo artículo declara uno de los principios más importantes del Derecho internacional, y es que ningún Estado puede invocar la ley interna para desatender mandatos del Derecho internacional que haya aceptado, y menos aún si se trata de derechos humanos o sus garantías.

Por su parte, en el mismo texto, en el art. 137, advierte la supremacía de la Constitución por sobre cualquier otro documento ${ }^{27}$; no obstante, en esta Constitución sí encontramos especial referencia a los derechos humanos en el art. $145^{28}$, donde se señala que existe un orden supranacional para los derechos humanos si se tiene una previa aprobación del Congreso. Es decir, sí existe una supraconstitucionalidad por parte de los derechos fundamentales, empero debe existir un proceso de autorización de la Cámara correspondiente.

${ }^{26}$ Constitución Nacional de la República del Paraguay, 1992.

27 «Art. 137. De la supremacía de la Constitución. La ley suprema de la República es la Constitución. Ésta, los tratados, convenios y acuerdos internacionales aprobados y ratificados, las leyes dictadas por el Congreso y otras disposiciones jurídicas de inferior jerarquía, sancionadas en consecuencia, integran el Derecho positivo nacional en el orden de prelación enunciado» (Constitución Nacional de la República del Paraguay, 1992).

${ }^{28}$ «Art. 145. Del orden jurídico supranacional. La República del Paraguay, en condiciones de igualdad con otros Estados, admite un orden jurídico supranacional que garantice la vigencia de los derechos humanos, de la paz, de la justicia, de la cooperación y del desarrollo, en lo político, económico, social y cultural. Dichas decisiones sólo podrán adoptarse por mayoría absoluta de cada Cámara del Congreso» (Constitución Nacional de la República del Paraguay, 1992). 
De alguna manera queda en entredicho la fuerza de los derechos fundamentales en este tema, puesto que requieren autorización para entrar como Derecho supraconstitucional. De todas formas, nos quedamos con la cláusula abierta transcrita donde se pueden incluir cualesquiera derechos fundamentales inherentes al ser humano.

Por su parte, la Constitución uruguaya en su art. $72^{29}$ establece su cláusula abierta y utiliza para ello los puntos 1 y 2 de los EBCA, referentes a la inherencia a la persona humana y a la forma de gobierno.

«Art. 72. La enumeración de derechos, deberes y garantías hecha por la Constitución no excluye los otros que son inherentes a la personalidad humana o se derivan de la forma republicana de gobierno» ${ }^{30}$.

Como podemos observar, el texto constitucional uruguayo, al igual que el paraguayo, menciona la frase «personalidad humana» cuando en estricto sentido debiera utilizarse la expresión «persona humana»; no obstante, para efectos de la exposición que ofrecemos lo tomamos para cualquier efecto con el significado de la segunda acepción.

En el caso de la Constitución colombiana, el art. 94 nos presenta la cláusula de apertura en consonancia con el texto anterior:

«Art. 94. La enunciación de los derechos y garantías contenidos en la Constitución y en los convenios internacionales vigentes no debe entenderse como negación de otros que, siendo inherentes a la persona humana, no figuren expresamente en ellos».

Interesa hacer notar que Colombia asimila los derechos humanos de la Constitución con los de los convenios internacionales vigentes; en otras palabras, la apertura para los derechos de convenios internacionales vigentes se da por un hecho. También aclara que, además de los derechos contenidos en estos dos instrumentos, el catálogo constitucional está abierto para cualquier otro derecho que cumpla con la exigencia de ser inherente a la persona humana. Presumimos que la fuente principal de los derechos que probablemente puedan ingresar en el catálogo colombiano serían los tratados internacionales que no son vigentes en el ordenamiento interno, sin que éstos sean los únicos.

29 Constitución de la República Oriental del Uruguay, 1967.

30 El texto asimila «personalidad humana» con «persona humana». Consideramos que lo correcto es utilizar esta segunda expresión. 
Por tanto, encontramos que el constituyente colombiano toma en cuenta el punto 1 y el punto 6 de los EBCA cuando se trata de la apertura a los derechos humanos internacionales.

Esta Constitución, además, establece en el art. 44 los derechos fundamentales esenciales y termina el párrafo explicando que: «Gozarán también de los demás derechos consagrados en la Constitución, en las leyes y en los tratados internacionales ratificados por Colombia» ${ }^{31}$. Por su parte, el apartado 93 confirma la prevalencia de los tratados internacionales en el orden interno y además la necesidad de realizar la interpretación constitucional con base en estos instrumentos internacionales; por último, reconoce la competencia de la Corte Penal Internacional.

En el caso de Venezuela, encontramos varios artículos referentes al tema de los derechos humanos. El art. 19 menciona la importancia del respeto y la garantía obligatoria para todos los órganos de poder de conformidad con la Constitución y con los tratados de derechos humanos ${ }^{32}$. La cláusula de apertura se encuentra establecida en el art. 22, al igual que en las Constituciones que nos preceden, e indica que no existe negación de otros inherentes a la persona humana, por tanto, utiliza el punto 1 de los EBCA, empero, al igual que el caso colombiano, la Constitución venezolana asimila en este artículo la importancia de los derechos humanos contenidos en la Constitución con los de los instrumentos internacionales sobre derechos humanos, por lo cual también recurre al punto 6 de los EBCA:

«Art. 22. La enunciación de los derechos y garantías contenidos en esta Constitución y en los instrumentos internacionales sobre derechos humanos no debe entenderse como negación de otros que, siendo inherentes a la persona, no figuren expresamente en ellos. La falta de ley reglamentaria de estos derechos no menoscaba el ejercicio de los mismos».

31 «Art. 44. Son derechos fundamentales de los niños: la vida, la integridad física, la salud y la seguridad social, la alimentación equilibrada, su nombre y nacionalidad, tener una familia y no ser separado de ella, el cuidado y amor, la educación y la cultura, la recreación y la libre expresión de su opinión. Serán protegidos contra toda forma de abandono, violencia física o moral, secuestro, venta, abuso sexual, explotación laboral o económica y trabajos riesgosos. Gozarán también de los demás derechos consagrados en la Constitución, en las leyes y en los tratados internacionales ratificados por Colombia» (Constitución Política de Colombia, 1991).

32 «Art. 19. El Estado garantizará a toda persona, conforme al principio de progresividad y sin discriminación alguna, el goce y ejercicio irrenunciable, indivisible e interdependiente de los derechos humanos. Su respeto y garantía son obligatorios para los órganos del poder público de conformidad con esta Constitución, con los tratados sobre derechos humanos suscritos y ratificados por la República y con las leyes que los desarrollen» (Constitución de la República Bolivariana de Venezuela, 1999). 
Si leemos además el art. 23 vamos a encontrar más claramente que Venezuela considera a los tratados internacionales sobre derechos humanos con la misma jerarquía de la Constitución, pero aclara que cuando el ejercicio de los mismos sea más favorable que el estipulado en el texto constitucional tendrán prevalencia en el orden interno. Por lo demás, deja claro que son de aplicación inmediata y directa por los tribunales y demás órganos públicos ${ }^{33}$.

En el particular caso de Venezuela nos permitimos expresar nuestra opinión en cuanto a que parece existir un desfase entre lo que dispone el documento constitucional y la realidad, aún más porque en su art. 31 estipula que por el derecho que tiene toda persona a solicitar ayuda internacional en el caso de violación de derechos humanos, el Estado debe adoptar los procedimientos adecuados para acatar las decisiones emanadas de dichos órganos ${ }^{34}$. No obstante, fue precisamente Venezuela quien denunció en septiembre de 2012 la Convención Americana de Derechos Humanos aduciendo que «en los últimos años la práctica de los órganos regidos por el Pacto de San José, tanto la Comisión Interamericana de Derechos Humanos como la Corte Interamericana de Derechos Humanos, se ha alejado de los sagrados principios que están llamados a proteger, convirtiéndose en un arma política arrojadiza destinada a minar la estabilidad de determinados gobiernos».

Otra razón que da el Estado venezolano para denunciar esta Convención es que, al haber incorporado en su normativa los artículos anteriormente analizados, el país está a la vanguardia en derechos humanos en cuanto a normativa y en cuanto a instituciones garantistas de los mismos, por lo cual tiene la autoridad moral y política para denunciar a dichos órganos del sistema interamericano.

33 «Art. 23. Los tratados, pactos y convenciones relativos a derechos humanos suscritos y ratificados por Venezuela tienen jerarquía constitucional y prevalecen en el orden interno, en la medida en que contengan normas sobre su goce y ejercicio más favorables a las establecidas por esta Constitución y en las leyes de la República, y son de aplicación inmediata y directa por los tribunales y demás órganos del poder público» (Constitución de la República Bolivariana de Venezuela, 1999).

34 «Art. 31. Toda persona tiene derecho, en los términos establecidos por los tratados, pactos y convenciones sobre derechos humanos ratificados por la República, a dirigir peticiones o quejas ante los órganos internacionales creados para tales fines con el objeto de solicitar el amparo a sus derechos humanos. El Estado adoptará, conforme a procedimientos establecidos en esta Constitución y la ley, las medidas que sean necesarias para dar cumplimiento a las decisiones emanadas de los órganos internacionales previstos en este artículo» (Constitución de la República Bolivariana de Venezuela, 1999). 
No obstante, debido a los últimos sucesos en ese país parece ser que los derechos humanos y su eficacia no son una de las prioridades para el gobierno venezolano.

Honduras también contiene la cláusula clásica de apertura al DIDH. Así, en su art. 63 estipula que no existe negación para otros derechos no especificados dentro del texto constitucional. El texto expresa los puntos 2, 3 y 4 de los EBCA, en consecuencia, la forma de gobierno, la dignidad y el principio de soberanía:

«Art. 63. Las declaraciones, derechos y garantías que enumera esta Constitución no serán entendidos como negación de otras declaraciones, derechos y garantías no especificadas que nacen de la soberanía, de la forma republicana, democrática y representativa de gobierno, y de la dignidad del hombre» ${ }^{35}$.

La Constitución peruana ${ }^{36}$, al igual que la hondureña, funda su cláusula de apertura en los puntos 2, 3, 4 de los EBCA, referentes a la forma de gobierno, la dignidad y el principio de soberanía; además menciona otros derechos de naturaleza análoga, es decir, de la misma esencia que los derechos fundamentales, por lo cual inferimos aquí también el punto 5 de los EBCA:

«Art. 3. ${ }^{\circ}$ La enumeración de los derechos establecidos en este capítulo no excluye los demás que la Constitución garantiza ni otros de naturaleza análoga o que se fundan en la dignidad del hombre, o en los principios de soberanía del pueblo, del Estado democrático de Derecho y de la forma republicana de gobierno».

Continuamos el comparativo con Argentina, cuya Constitución toma en cuenta los elementos 2 y 4 de los EBCA arriba señalados, correspondientes a la forma de gobierno y al principio de soberanía del pueblo. De esta forma encontramos el art. $33^{37}$, el cual establece que:

«Las declaraciones, derechos y garantías que enumera la Constitución no serán entendidos como negación de otros derechos y garantías no enumerados, pero que nacen del principio de la soberanía del pueblo y de la forma republicana de gobierno».

${ }^{35}$ Constitución Política de la República de Honduras, 1982.

${ }^{36}$ Constitución Política del Perú, 1993.

37 Constitución Nacional de la Nación Argentina, 1994. 
De lo anterior podemos deducir que, efectivamente, la Constitución argentina tiene una apertura real para cualquier derecho fundamental que no esté contenido ya en su texto. Ahora bien, en su art. $75.22^{38}$ menciona expresamente que los tratados de derechos humanos tienen jerarquía superior a las leyes, aunque no las asimila a la Constitución; sin embargo, lo interesante es que en este artículo hace una enumeración de documentos específicos a los cuales sí les otorga ese rango, y a «los demás tratados y convenciones de derechos humanos» se les otorgarán cuando se aprueben específicamente para recibir esa jerarquía.

En términos generales entendemos que, aunque la enumeración de instrumentos esté plasmada constitucionalmente, si algún derecho no estuviera dentro de esos instrumentos de todas formas entraría a formar parte del catálogo protegido constitucionalmente a través de la cláusula de apertura del art. 33.

La Constitución brasileña ${ }^{39}$, por su parte, en su art. 5.2 abre su catálogo de derechos y considera los elementos 2 y 6 , la forma de gobierno y los tratados internacionales:

«2. ${ }^{\circ}$ Los derechos y garantías expresadas en esta Constitución no excluyen otros derivados del régimen y de los principios por ella adoptados, o de los tratados internacionales en que la República Federativa de Brasil sea parte».

${ }^{38} \mathrm{El}$ art. 75 se refiere a las funciones del Congreso, y en el inciso 22 explica que le corresponde a este órgano: «Aprobar o desechar tratados concluidos con las demás naciones y con las organizaciones internacionales y los concordatos con la Santa Sede. Los tratados y concordatos tienen jerarquía superior a las leyes. La Declaración Americana de los Derechos y Deberes del Hombre; la Declaración Universal de Derechos Humanos; la Convención Americana sobre Derechos Humanos [1]; el Pacto Internacional de Derechos Económicos, Sociales y Culturales; el Pacto Internacional de Derechos Civiles y Políticos y su Protocolo Facultativo [2]; la Convención sobre la Prevención y la Sanción del Delito de Genocidio [3]; la Convención Internacional sobre la Eliminación de todas las Formas de Discriminación Racial [4]; la Convención sobre la Eliminación de todas las Formas de Discriminación contra la Mujer [5]; la Convención contra la Tortura y otros Tratos o Penas Crueles, Inhumanos o Degradantes [6]; la Convención sobre los Derechos del Niño [7]; en las condiciones de su vigencia, tienen jerarquía constitucional, no derogan artículo alguno de la primera parte de esta Constitución y deben entenderse complementarios de los derechos y garantías por ella reconocidos. Sólo podrán ser denunciados, en su caso, por el poder ejecutivo nacional, previa aprobación de las dos terceras partes de la totalidad de los miembros de cada Cámara. Los demás tratados y convenciones sobre derechos humanos, luego de ser aprobados por el Congreso, requerirán del voto de las dos terceras partes de la totalidad de los miembros de cada Cámara para gozar de la jerarquía constitucional».

39 Constitución Política de la República Federativa de Brasil, 1988. 
Se refuerza esta posición de apertura, puesto que en el inciso primero del artículo comentado se establece categóricamente que:

«1. ${ }^{\circ}$ Las normas definidoras de los derechos y garantías fundamentales son de aplicación inmediata».

Por su parte, la Constitución panameña consagra en su art. $17^{40}$ una cláusula abierta y expone que los incluidos en el texto constitucional constituyen mínimos. En este sentido, la expansibilidad del derecho se encuentra abierta para cualquier otro que implique los puntos 3 y 5 de los EBCA, sobre la dignidad de la persona y los derechos fundamentales:

«Art. 17. Las autoridades de la República están instituidas para proteger en su vida, honra y bienes a los nacionales dondequiera se encuentren y a los extranjeros que estén bajo su jurisdicción; asegurar la efectividad de los derechos y deberes individuales y sociales, y cumplir y hacer cumplir la Constitución y la Ley. Los derechos y garantías que consagra esta Constitución deben considerarse como mínimos y no excluyentes de otros que incidan sobre los derechos fundamentales y la dignidad de la persona».

Continuamos con la Constitución de Ecuador, la que, al igual que las Constituciones colombiana y venezolana, otorga una protección y eficacia igual a los derechos procedentes del propio texto y de los tratados internacionales de derechos humanos ${ }^{41}$. En este sentido da por hecho que los derechos fundamentales son los que se encuentran en el texto constitucional y en los instrumentos internacionales de derechos humanos; por consiguiente, la apertura a los derechos provenientes de estos convenios se considera un hecho. En consecuencia, entendemos que su constituyente utiliza el punto 6 de los EBCA cuando expone su cláusula de apertura que encontramos en el inciso 7 del art. 11, donde se expresa la apertura a cualquier otro derecho que se derive de la dignidad de las personas y recurre al hacerlo al punto 3 de los EBCA.

40 Constitución Política de la República de Panamá, 1972.

${ }^{41}$ «Art. 11.3. Los derechos y garantías establecidos en la Constitución y en los instrumentos internacionales de derechos humanos serán de directa e inmediata aplicación por y ante cualquier servidora o servidor público, administrativo o judicial, de oficio o a petición de parte. Para el ejercicio de los derechos y las garantías constitucionales no se exigirán condiciones o requisitos que no estén establecidos en la Constitución o la ley. Los derechos serán plenamente justiciables. No podrá alegarse falta de norma jurídica para justificar su violación o desconocimiento, para desechar la acción por esos hechos ni para negar su reconocimiento» (Constitución de la República de Ecuador, 2008). 
«Art. 11.7. El reconocimiento de los derechos y garantías establecidos en la Constitución y en los instrumentos internacionales de derechos humanos no excluirá los demás derechos derivados de la dignidad de las personas, comunidades, pueblos y nacionalidades, que sean necesarios para su pleno desenvolvimiento».

Además del artículo transcrito es importante comentar el art. 417, en cuanto explica que cuando se trata de instrumentos internacionales de derechos humanos se aplicarán los principios pro ser humano y de no restricción de derechos, por lo que afirma que se deben aplicar de manera directa y se refiere a la cláusula abierta especificada en el art. 11.7 constitucional $^{42}$.

En el caso de Puerto Rico, cuya Constitución contiene apenas nueve $\operatorname{artículos}^{43}$, la cláusula abierta se manifiesta en el art. 2, sección 19. Para analizar este texto nos permitimos asimilar la expresión «derechos pertenecientes al pueblo en una democracia» como derechos fundamentales, de esta forma podemos hacer coincidir la cláusula de apertura con el punto 5 de los EBCA. La redacción del texto es la siguiente:

«Art. 2, sección 19. La enumeración de derechos que antecede no se entenderá en forma restrictiva ni supone la exclusión de otros derechos pertenecientes al pueblo en una democracia y no mencionados específicamente. Tampoco se entenderá como restrictiva de la facultad de la Asamblea Legislativa para aprobar leyes en protección de la vida, la salud y el bienestar del pueblo».

La Constitución más joven de Iberoamérica es en este momento la Constitución de República Dominicana ${ }^{44}$, la cual expone claramente en el apartado primero del art. 74 que no se excluyen otros derechos y garantías de la misma naturaleza que los derechos y garantías fundamentales. Coincide, por tanto, con la Constitución anterior, en el sentido de que toma para incorporar la cláusula abierta el punto 5 de los EBCA:

«Art. 74. Principios de reglamentación e interpretación. La interpretación y reglamentación de los derechos y garantías fundamentales reconocidos en la presente Constitución se rigen por los principios siguientes:

42 «Art. 417. Los tratados internacionales ratificados por Ecuador se sujetarán a lo establecido en la Constitución. En el caso de los tratados y otros instrumentos internacionales de derechos humanos se aplicarán los principios pro ser humano, de no restricción de derechos, de aplicabilidad directa y de cláusula abierta establecidos en la Constitución».

${ }^{43}$ Constitución del Estado Libre Asociado de Puerto Rico.

${ }^{44}$ Constitución de la República Dominicana, 2010. 
1) No tienen carácter limitativo y, por consiguiente, no excluyen otros derechos y garantías de igual naturaleza».

No obstante, si nos detenemos a leer el siguiente inciso intuimos un dejo de preocupación por el constituyente dominicano cuando aclara que «únicamente por medio de ley se podrán regular el ejercicio de derechos y garantías fundamentales» ${ }^{45}$. Seguidamente encontramos el inciso tercero, que de alguna manera minimiza la ordenanza anterior, y es que en cuanto a tratados, pactos y convenciones sobre derechos humanos, la Constitución admite que tienen jerarquía constitucional y que son de aplicación directa e inmediata por los tribunales y otros órganos estatales ${ }^{46}$; igualmente trata el tema de la interpretación conforme al principio pro persona. Según nuestro punto de vista, se nota alguna imprecisión entre los incisos segundo y tercero.

En el continente europeo nos encontramos la Constitución de Portugal, la cual contiene su cláusula de apertura en el art. 16 y recurre a los puntos 6 y 7 de los EBCA, referentes al Derecho internacional y a la ley:

«Art. 1647. Extensión de los derechos. Los derechos fundamentales consagrados en la Constitución no excluyen cualesquiera otros que resulten de las leyes y de las normas aplicables de Derecho internacional».

En el precepto segundo del mismo artículo se encuentra estipulada la orden de interpretación de los artículos constitucionales, de acuerdo a la Declaración Universal de los Derechos del Hombre, de la siguiente manera:

«2. Los preceptos constitucionales y legales relativos a los derechos fundamentales deberán ser interpretados e integrados en armonía con la Declaración Universal de los Derechos del Hombre».

45 «Art. 74.2) Sólo por ley, en los casos permitidos por esta Constitución, podrá regularse el ejercicio de los derechos y garantías fundamentales, respetando su contenido esencial y el principio de razonabilidad».

${ }_{46}$ «Art. 74.3) Los tratados, pactos y convenciones relativos a derechos humanos suscritos y ratificados por el Estado dominicano tienen jerarquía constitucional y son de aplicación directa e inmediata por los tribunales y demás órganos del Estado. 4 ) Los poderes públicos interpretan y aplican las normas relativas a los derechos fundamentales y sus garantías en el sentido más favorable a la persona titular de los mismos y, en caso de conflicto entre derechos fundamentales, procurarán armonizar los bienes e intereses protegidos por esta Constitución».

${ }^{47}$ Constitución de la República Portuguesa, 1976. 
Nos llaman la atención dos situaciones que emanan de esta transcripción. La primera en el sentido de que está limitando la interpretación respectiva a un documento específico, sin valorar que pueden existir otros documentos base para la adecuada exégesis de los mismos. La segunda es que se menciona la Declaración Universal de los Derechos del Hombre en particular, sin aclarar si es la Declaración Universal de los Derechos Humanos o bien la Declaración de los Derechos del Hombre y del Ciudadano. Parece haberse deducido que el documento comentado es el primero mencionado.

La Constitución costarricense ${ }^{48}$ también menciona el punto 7 de los EBCA, referente a la ley, e incluye el elemento 8 de nuestra descripción, el cual únicamente es utilizado por Costa Rica y que concierne al principio cristiano de justicia social. Dicha cláusula abierta se encuentra establecida en el art. 74 para otros derechos no enumerados en el documento constitucional:

«Art. 74. Los derechos y beneficios a que este capítulo se refiere son irrenunciables. Su enumeración no excluye otros que se deriven del principio cristiano de justicia social y que indique la ley; serán aplicables por igual a todos los factores concurrentes al proceso de producción y reglamentados en una legislación social y de trabajo, a fin de procurar una política permanente de solidaridad nacional».

Nicaragua, por su parte, desde su artículo sexto ${ }^{49}$ manifiesta un respeto y una preeminencia de los derechos humanos. En el art. 46 es donde se estipula la cláusula de apertura al DIDH. En este texto no encontramos la claridad de los anteriores; sin embargo, es notorio que se trata de una cláusula abierta que utiliza el punto 1 respecto de la inherencia a la persona humana, y en cierta forma se refiere también al punto 6 de los EBCA, con especial detalle a ciertos instrumentos internacionales:

«Art. 46. En el territorio nacional toda persona goza de la protección estatal y del reconocimiento de los derechos inherentes a la perso-

48 Constitución Política de la República de Costa Rica, 1949.

49 «Art. 6. Nicaragua es un Estado independiente, libre, soberano, unitario e indivisible. Se constituye en un Estado democrático y social de Derecho que promueve como valores superiores la dignificación del pueblo a través de su ordenamiento jurídico, la libertad, la justicia, la igualdad, la solidaridad, la responsabilidad social y, en general, la preeminencia de los derechos humanos, la ética y el bien común. Las ciudadanas y ciudadanos y la familia son elementos protagónicos en la toma de decisiones, planificación y gestión de los asuntos públicos del Estado» (Constitución Política de la República de Nicaragua, 1986, con reformas de 2014). 
na humana, del irrestricto respeto, promoción y protección de los derechos humanos, y de la plena vigencia de los derechos consignados en la Declaración Universal de los Derechos Humanos; en la Declaración Americana de Derechos y Deberes del Hombre; en el Pacto Internacional de Derechos Económicos, Sociales y Culturales, y en el Pacto Internacional de Derechos Civiles y Políticos de la Organización de las Naciones Unidas y en la Convención Americana de Derechos Humanos de la Organización de Estados Americanos».

Lo interesante del texto es que, si bien es cierto que menciona los instrumentos generales más emblemáticos de los derechos humanos y que efectivamente está la cláusula de apertura, por otra parte podría interpretarse que se cierra este catálogo y que impide que cualquier otro derecho no contemplado en estos tratados pueda adherirse posteriormente. Se podría comprobar esta posición con la lectura del art. $182^{50}$, el cual dispone la jerarquía de la Constitución sobre cualquier otra ley, tratado, decreto, etc. Sin embargo, si realizamos una interpretación pro bomine diremos que al estar consagrados los derechos humanos en los pactos y convenciones mencionados en el art. 46, pero sobre todo por los primeros renglones, donde establece la protección y el reconocimiento de los derechos inherentes a la persona humana, entendemos que, aunque se mencionen esos tratados específicos, no implica que otros derechos de otros instrumentos no puedan venir a tener la protección mencionada en la primera parte del artículo.

Ahora bien, al adentrarnos en la Constitución mexicana notamos que México tampoco contiene una cláusula abierta tan clara como las anteriormente estudiadas; no obstante, se infiere de su artículo primero que está abierto a los derechos que emanan de los tratados internacionales de derechos humanos; aún más, establece que las normas de derechos humanos deben interpretarse de conformidad con su propio texto constitucional, pero también con base en los tratados internacionales de los que México sea parte (en este sentido anteponen el principio pro bomine para cualquier decisión). Con este artículo el Estado manifiesta que efectivamente la jerarquía de los tratados internacionales sobre derechos humanos está al mismo nivel que la Constitución, por tanto, gozan de las mis-

\footnotetext{
50 «Art. 182. La Constitución Política es la carta fundamental de la República; las demás leyes están subordinadas a ella. No tendrán valor alguno las leyes, tratados, decretos, reglamentos, órdenes o disposiciones que se le opongan o alteren sus disposiciones» (Constitución Política de la República de Nicaragua, 1986, con reformas de 2014).
} 
mas garantías de protección y efectividad que los contenidos dentro del documento constitutivo.

«Art. 1. ${ }^{\circ}$ En los Estados Unidos Mexicanos todas las personas gozarán de los derechos humanos reconocidos en esta Constitución y en los tratados internacionales de los que el Estado mexicano sea parte, así como de las garantías para su protección, cuyo ejercicio no podrá restringirse ni suspenderse, salvo en los casos y bajo las condiciones que esta Constitución establece.

Las normas relativas a los derechos humanos se interpretarán de conformidad con esta Constitución y con los tratados internacionales de la materia favoreciendo en todo tiempo a las personas la protección más amplia».

Podríamos agregar, para seguir con nuestro esquema, que México recurre al punto 6 de los EBCA por tomar como referencia para la apertura de nuevos derechos a los tratados internacionales sobre derechos humanos.

Ahora bien, si regresamos al continente europeo nos encontramos el caso español, el cual ha sido muy analizado, puesto que no es una cláusula abierta redactada en los términos de las Constituciones que nos preceden; no obstante, se ha llegado a la conclusión de que efectivamente es una cláusula de apertura.

En este sentido se ha considerado que en el primer apartado del art. 10 es donde se consagra el principio de «cláusula abierta», lista abierta o «no tipicidad» de los derechos fundamentales. Localizamos la cláusula de apertura en el art. 10 constitucional español ${ }^{51}$ :

«Art. 10.1. La dignidad de la persona, los derechos inviolables que le son inherentes, el libre desarrollo de la personalidad, el respeto a la ley y a los derechos de los demás son fundamento del orden político y de la paz social».

En congruencia con el esquema de los EBCA, podríamos extraer de este apartado que el constituyente español incluye el punto 1 sobre la inherencia a la persona humana y de alguna manera el punto 7 respecto de la legalidad, sin que exista claridad del todo en este último elemento.

Ahora bien, consideramos que al no estar tan clara la norma del primer inciso, el segundo lo completa. En este sentido, este apartado habla de

${ }^{51}$ Constitución Española, 1978. 
la interpretación de los derechos constitucionales con base en los tratados internacionales sobre derechos humanos:

«Art. 10.2. Las normas relativas a los derechos fundamentales y a las libertades que la Constitución reconoce se interpretarán de conformidad con la Declaración Universal de Derechos Humanos y los tratados y acuerdos internacionales sobre las mismas materias ratificados por España».

El art. 10.2, al vincular la interpretación de los derechos fundamentales y libertades que la Constitución reconoce a los tratados sobre las mismas materias ratificados por España, expresa en alguna medida la apertura del Estado al $\mathrm{DIDH}^{52}$. En consecuencia, consideramos que el punto 6 de los EBCA también se toma en cuenta para esta apertura a los derechos internacionales.

Por consiguiente, no se trata ya sólo de la incorporación al Derecho interno de los acuerdos, declaraciones, convenciones, etc., que tengan por objeto los derechos de la persona, que esto no es ninguna novedad; se trata, además y sobre todo, de adecuar la actuación de los intérpretes de la Constitución a los contenidos de aquellos tratados, que devienen así, por imperativo constitucional, canon hermenéutico de la regulación de los derecho y libertades en la Norma Fundamental ${ }^{53}$.

Por su parte, la Constitución de El Salvador no presenta cláusulas de apertura de forma explícita, únicamente aclara el valor que le otorga encima de la ley a los tratados internacionales sobre derechos humanos; así se evidencia de su art. $144^{54}$. Por tanto, podríamos decir que la jerarquía de los tratados internacionales es que son subconstitucionales. No obstante, la Constitución no menciona los instrumentos específicamente de derechos humanos, es decir, los trata de igual manera que los del DIC. El artículo referido es el siguiente:

«Art. 144. Los tratados internacionales celebrados por El Salvador con otros Estados o con organismos internacionales constituyen leyes de la República al entrar en vigencia, conforme a las disposiciones del mismo tra-

52 Así también, J. CAstellá Andreu, «El art. 10.2 de la Constitución como canon de interpretación de los derechos fundamentales», en M. Á. Aparicio PéreZ (coord.), Derechos constitucionales y pluralidad de ordenamientos, Barcelona, Cedecs, 2001, p. 146.

53 A. SAIz ARnAIz, La apertura constitucional al Derecho internacional y europeo de los derechos humanos. El art. 10.2 de la Constitución Española, Madrid, Consejo General del Poder Judicial, 1999, p. 53.

54 Constitución de la República de El Salvador, 1983. 
tado y de esta Constitución. La ley no podrá modificar o derogar lo acordado en un tratado vigente para El Salvador. En caso de conflicto entre el tratado y la ley, prevalecerá el tratado».

Consideramos que este artículo, aunque abre el catálogo de los derechos en el Estado salvadoreño, no se puede colocar en el esquema de cláusulas abiertas a los derechos humanos internacionales, por lo cual, para la Constitución de El Salvador no aplica el diseño de los EBCA.

Cerramos este análisis no sin antes comentar que de Cuba no transcribimos su artículo de cláusula abierta, porque no está considerada dentro de su texto constitucional. En consecuencia, y como resumen de lo expuesto, podemos exponer los siguientes cuadros ${ }^{55}$ :

\section{Elementos Básicos de las Cláusulas de Apertura (EBCA) en Constituciones iberoamericanas}

\begin{tabular}{|c|l|}
\hline Número & \multicolumn{1}{|c|}{$E B C A$} \\
\hline 1 & Inherencia a la persona humana. \\
\hline 2 & Forma de gobierno (democrático, participativo, etc.). \\
\hline 3 & Dignidad humana. \\
\hline 4 & Principio de soberanía. \\
\hline 5 & Derechos fundamentales y/o de su misma naturaleza. \\
\hline 6 & Derecho internacional y tratados internacionales. \\
\hline 7 & Legalidad. \\
\hline 8 & Principio cristiano de justicia social. \\
\hline
\end{tabular}

EBCA considerados particularmente en las Constituciones iberoamericanas

\begin{tabular}{|c|c|c|c|c|c|c|c|}
\hline Chile & Bolivia & Guatemala & Paraguay & Uruguay & Colombia & Venezuela & Honduras \\
\hline 1 y 6 & N. A.* & 1 & 1 & 1 y 2 & 1 y 6 & 1 y 6 & 2,3 y 4 \\
\hline Perú & Argentina & Brasil & Panamá & Ecuador & P. Rico & R. Dominicana & Portugal \\
\hline $2,3,4$ y 5 & 2 y 4 & 2 y 6 & 3 y 5 & 3 y 6 & 5 & 5 & 6 y 7 \\
\hline Costa Rica & Nicaragua & México & España & El Salvador & Cuba & & \\
\hline 7 y 8 & 1 y 6 & 6 & 1 y 6 & N. A.** & N. A.** & & \\
\hline
\end{tabular}

* No aplica porque no contiene EBCA.

** No aplica porque no tiene cláusula de apertura.

55 Cuadros de elaboración propia. El primero se refiere a los elementos básicos que consideran los Estados iberoamericanos a la hora de estipular la cláusula abierta a los derechos humanos internacionales dentro de su Constitución Política. El segundo cuadro indica qué elementos consideró cada Estado particularmente y plasmó en su texto constitutivo. 
Como corolario de esta investigación podemos concluir que la existencia de una norma referente a los derechos fundamentales no enunciados o no enumerados en la Constitución de un Estado constituye una característica del Derecho constitucional iberoamericano ${ }^{56}$. Esta enunciación o enumeración de algunos derechos lleva consigo la consecuencia de que si estos derechos no están expresamente declarados, pero poseen las características que exigen los textos constitucionales, se consideran igualmente reconocidos y deben ser, por ende, protegidos y garantizados. De este modo, se mantiene abierto, renovado y actualizado el catálogo de derechos constitucionalmente protegidos.

Compartimos con Nikken ${ }^{57}$ que la internacionalización no significa que la comunidad internacional asume como una tarea propia la de respetar y garantizar los derechos humanos de cada persona en este mundo. Ésa es una tarea del Estado a través de su orden jurídico, su aparato administrativo y su sistema judicial. El papel del DIDH es el de estimular en una gradación diversa a los mecanismos nacionales para que resuelvan sus carencias en ese cometido. Así, este tipo de incentivos pueden ser desde promoción dentro de la cooperación internacional, hasta la asignación de responsabilidades por órganos internacionales.

Las cláusulas abiertas se convierten en la primera técnica directa que ha conducido a la aplicación inmediata de los tratados internacionales sobre derechos humanos por los tribunales nacionales en el orden interno.

En consecuencia, si analizamos la mayoría de las disposiciones constitucionales y, a la vez, las cláusulas de apertura incorporadas al texto constitucional, comprobamos que no constituyen catálogos separados, sino complementarios ${ }^{58}$. Por consiguiente, su protección y tratamiento debe ser el mismo que gozan los derechos estructurados expresamente dentro de la Constitución estatal.

En concordancia con lo anterior, coincidimos con Canosa Usera cuando explica que este tipo de normas vienen a completar e integrar la lista de derechos incluida en la Carta Fundamental, con la consideración de las otras tablas de derechos operantes en el ámbito internacional y reconocidas por el Estado; de esta forma, los textos interna-

${ }^{56}$ H. Gros EsPiell, «Los derechos humanos no enunciados o no enumerados en el constitucionalismo americano y en el art. 29.c) de la Convención Americana sobre Derechos Humanos», Anuario Iberoamericano de Justicia Constitucional, núm. 4 (2000), pp. 145-146.

57 P. NikKen, «El Derecho Internacional de los Derechos Humanos en el Derecho interno», op. cit., 18

58 Con la misma idea ibid., p. 53. 
cionales comentados actuarían integrativamente como subsidiarios del constitucional $^{59}$.

En este orden de ideas, la discusión de si el catálogo de derechos fundamentales es cerrado y, por tanto, la protección especial es solamente para los derechos insertos literalmente en el texto constitucional, también la dejaríamos de lado, puesto que al establecerse una cláusula abierta a los derechos de los instrumentos se estaría ampliando necesariamente la gama de derechos que deben ser protegidos.

Algunos autores tienen la opinión de que si bien es cierto que se abre el catálogo de los derechos con este tipo de cláusulas, los derechos que se integran gracias a ellas son «derechos materialmente pero no formalmente», es decir, no se constitucionalizan ${ }^{60}$. En contraposición a esta idea, otros autores consideran que al existir este tipo de normas dentro del texto constitucional, de alguna manera «constitucionalizan» las normas internacionales o bien se convierten en normas que constituyen parámetros de constitucionalidad para las normas internas infraconstitucionales ${ }^{61}$.

En nuestra opinión, y como ya lo hemos expresado, es claro que desde el momento en el cual la Constitución los admite al lado de los derechos fundamentales que contiene, deben ser garantizados de la misma manera que si fueran derechos constitucionales, por lo que para nosotros no habría ningún problema en denominar el término del proceso como constitucionalización de los derechos humanos ${ }^{62}$.

Lo que realmente nos interesa aclarar en este punto es que, aunque con esta apertura se establecen directamente los derechos humanos en la Constitución, no es estrictamente una constitucionalización de los acuerdos internacionales sobre este tema. Se abre la puerta para que entren los derechos de los tratados internacionales al Derecho interno de los Estados, pero el instrumento, por sí mismo, no se coloca paralelamente al texto constitucional, es decir, no es una constitucionalización de instru-

59 R. CANOSA USERA, Interpretación constitucional y fórmula politica, Madrid, Centro de Estudios Constitucionales, 1988, p. 193.

${ }^{60}$ A. Saiz Arnaiz, La apertura constitucional al Derecho internacional y europeo de los derechos humanos..., op. cit., p. 58.

${ }^{61}$ F. Ponce Martínez, Tribunal constitucional y tratados de derechos bumanos, op. cit., p. 152.

${ }^{62}$ C. LeÓn BAstos, «Proyecto de decreto que modifica la Constitución mexicana: apertura y pauta de interpretación de los derechos fundamentales», en J. P. ABREU SACRAMENTO y J. A. Le CleRCQ (coords.), La reforma humanista. Derechos bumanos y cambio constitucional en México, México DF, Konrad Adenauer y Miguel Ángel Porrúa, 2011, p. 234. 
mentos, sino una apertura a nuevos derechos que no se encuentran establecidos literalmente dentro del texto constitucional. Ahora bien, encontramos otro aspecto a tener en cuenta: si debe existir algún tipo de control especial para este «espacio abierto» a los derechos humanos de tratados internacionales. ¿Cómo de conveniente es dejarles esta vigilancia a los mismos intérpretes constitucionales? Esta idea, sobre todo, surge por parte de quienes no están tan de acuerdo con una apertura sin restricciones; en este sentido encontramos a Prieto Sanchís cuando menciona que este tipo de apertura del catálogo de derechos representa «una puerta abierta a la inseguridad jurídica y al activismo judicial», sobre todo porque si la apertura incluye también derechos prestaciones, «supondría la imposición de cargas con presunto respaldo constitucional, pero sin que medie una decisión legislativa» ${ }^{63}$.

En principio, consideramos que las cláusulas abiertas se refieren expresamente a derechos humanos, por lo cual «el peligro» que se correría es realmente inexistente. Estamos de acuerdo que una de las principales restricciones en el ámbito de los derechos humanos se consagra en el principio de que «el límite de un derecho está donde empieza el derecho del otro», por lo cual confiamos absolutamente estas situaciones al principio de proporcionalidad, al principio pro homine y al contenido esencial de los derechos humanos. Los cuales claramente deben ser aplicados por los jueces, quienes para ello deberán tener una capacitación sustancial en estos temas.

Finalmente, es importante anotar que los EBCA representan los valores más importantes para los Estados, por lo cual se apoyan en ellos para incorporar nuevos derechos, necesarios para los habitantes de cada Nación. Las cláusulas abiertas son una necesidad en las Constituciones actuales, puesto que no es posible una protección real de los derechos fundamentales si nos ajustamos a un catálogo cerrado de derechos. Todos tenemos derecho a que se nos reconozcan los derechos que provengan de la forma democrática de gobierno de nuestro Estado, a los que provienen del principio de soberanía, a los que emanan de los tratados internacionales, del principio cristiano de justicia social y los demás que indique la ley; pero principalmente a todos los que son inherentes a nuestra naturaleza como personas y nacen de nuestra dignidad humana. p. 160.

${ }^{63}$ L. Prieto Sanchís, Estudios sobre derechos fundamentales, Madrid, Debate, 1990, 


\section{BIBLIOGRAFÍA}

Ayala Corao, C., «La jerarquía constitucional de los tratados relativos a derechos humanos y sus consecuencias», en R. MÉndez (comp.), Derecho Internacional de los Derechos Humanos. Memoria del VII Congreso Iberoamericano de Derecho Constitucional, México DF, UNAM, 2002.

Brewer Carías, A., «La aplicación de los tratados internacionales sobre derechos humanos en el ordenamiento interno», en Estudio de Derecho constitucional comparado latinoamericano. El sistema interamericano de protección de los derechos bumanos y su repercusión en los órdenes jurídicos internos, México DF, Poder Judicial de la Federación de la Suprema Corte de Justicia de la Nación, 2008.

Cançado Trindade, A., «Desafíos de la protección internacional de los derechos humanos al final del siglo Xx», en Seminario sobre Derechos Humanos, La Habana-San José de Costa Rica, Instituto Interamericano de Derechos Humanos, 1997.

CANOSA Usera, R., Interpretación constitucional y fórmula política, Madrid, Centro de Estudios Constitucionales, 1998.

Castellà Andreu, J. M., «El art. 10.2 de la Constitución como canon de interpretación de los derechos fundamentales», en M. Á. ApAricio Pérez (coord.), Derechos constitucionales y pluralidad de ordenamientos, Barcelona, Cedecs, 2001.

DulitzKi, A., «La aplicación de los tratados sobre derechos humanos por los tribunales locales: un estudio comparado», en M. ABREGú (comp.), La aplicación de los tratados sobre derechos bumanos por los tribunales locales, Buenos Aires, Editores del Puerto, 2004.

Gros Espiell, H., «Los derechos humanos no enunciados o no enumerados en el constitucionalismo americano y en el art. 29.c) de la Convención Americana sobre Derechos Humanos», Anuario Iberoamericano de Justicia Constitucional, núm. 4 (2000).

Hitters, J. C., Derecho Internacional de los Derechos Humanos, t. I, Buenos Aires, Ediar, 1991.

- Derecho Internacional de los Derechos Humanos, t. II, Buenos Aires, Ediar, 1993.

LeÓn Bastos, C., «Proyecto de decreto que modifica la Constitución mexicana: apertura y pauta de interpretación de los derechos fundamentales», en J. P. Abreu y J. A. Le CleRcQ (coords.), La reforma bumanista. Derechos bumanos y cambio constitucional en México, México DF, Konrad Adenauer y Miguel Ángel Porrúa, 2011.

Nash Rojas, C., «La protección internacional de los derechos humanos», en Seminario internacional sobre el sistema interamericano de protección de los derechos bumanos y su repercusión en los órdenes jurídicos nacionales, México DF, Suprema Corte de Justicia, 2006. 
Carolina León y Victor A. Wong Cláusulas de apertura al Derecho internacional...

NikKen, P., «El Derecho Internacional de los Derechos Humanos en el Derecho interno», Revista del Instituto Interamericano de Derechos Humanos, núm. 57 (2013).

Pedro Sagués, N., «Mecanismos de incorporación de los tratados internacionales sobre derechos humanos al Derecho interno», en L. GonZÁLEZ (coord.), Presente y futuro de los derechos humanos. Ensayos en honor a Fernando Volio Jiménez, San José de Costa Rica, Instituto Interamericano de Derechos Humanos, 1998.

Piza Rocafort, R., y Trejos, G., Derecho Internacional de los Derechos Humanos: la Convención Americana, San José de Costa Rica, Juricentro, 1989.

Ponce Martínez, C. F., Tribunal constitucional y tratados de derechos bumanos, Zaragoza, Egido, 2002.

Prieto Sanchís, L., Estudios sobre derechos fundamentales, Madrid, Debate, 1990.

Saiz Arnaiz, A., La apertura constitucional al Derecho internacional y europeo de los derechos humanos. El art. 10.2 de la Constitución Española, Madrid, Consejo General del Poder Judicial, 1999.

Valverde, R., Los Derechos Humanos, San José de Costa Rica, EUNED, 1992.

Vargas Carreño, E., Introducción al Derecho Internacional, 2. ${ }^{a}$ ed., San José de Costa Rica, Juricentro, 1992. 